\title{
Comparison of Two Water Treatment Processes with Activated Aluminum Oxide
}

\author{
Junling Wang1 ${ }^{*}$, Xueming Wang1, Cuimin Feng ${ }^{1}$, Sheng Wei ${ }^{2}$ \\ ${ }^{1}$ Key Laboratory of Urban Stormwater System and Water Environment (Beijing University of Civil Engineering \\ and Architecture), Ministry of Education, Beijing, China \\ ${ }^{2}$ Beijing General Municipal Engineering Design \& Research Institute Co., Ltd., Beijing, China \\ Email: wangjunling@bucea.edu.cn
}

Received 3 April 2015; accepted 19 July 2015; published 22 July 2015

Copyright (C 2015 by authors and Scientific Research Publishing Inc.

This work is licensed under the Creative Commons Attribution International License (CC BY).

http://creativecommons.org/licenses/by/4.0/

(c) (i) 0 pen Access

\begin{abstract}
We focused on the need for the phosphorus removal in water plant process. As for surface water plant, the enhancement of phosphorus removal in purification process can raise the biological stability of effluent potable water. This study conducted the effect of two water treatment processes for phosphorus removal, including the PAC + AAL (the treatment process using poly aluminum chloride and activated aluminum oxide) and PFS + AAL (the treatment process using poly ferric sulfate and activated aluminum oxide). The aim is to use the adsorption capacity of activated aluminum oxide to increase the removal of phosphorus in filtration process. The result showed that the two processes both can remove the phosphorus concentration to reach below $10 \mu \mathrm{g} / \mathrm{L}$, and the PAC + AAL is the better process.
\end{abstract}

\section{Keywords}

Poly Aluminum Chloride, Poly Ferric Sulfate, Activated Aluminum Oxide, Phosphorus Removal, Surface Water

\section{Introduction}

To begin with we will provide a brief background on the biological stability of drinking water. The phosphorus is the limit factor in the potable water, and many research studies have been carried out on this topic [1]-[3]. If the soluble reactive phosphorus concentration is lower than $10 \mu \mathrm{g} / \mathrm{L}$ [4] [5] in the potable water which has high concentration of organic matter, the growth of bacteria would be limited in the water pipe. So it is important to research the phosphorus removal method in the water treatment plant in order to promote the biological stability

*Corresponding author.

How to cite this paper: Wang, J.L., Wang, X.M., Feng, C.M. and Wei, S. (2015) Comparison of Two Water Treatment Processes with Activated Aluminum Oxide. Journal of Water Resource and Protection, 7, 843-850.

http://dx.doi.org/10.4236/jwarp.2015.711068 
of tap water.

The adsorptive capacity of AAL (activated aluminum oxide) is so large that it can be used in water treatment process as an adsorptive filter media to enhance the removal of the phosphorus in the water purification process. At the same time, the PAC (poly aluminum chloride) and PFS (poly ferric sulfate) are usually used as coagulants in the water plant. The research was focused on the influence of the two coagulants combined with the adsorptive activated aluminum oxide filter media on the phosphorus removal and biological stability of tap water, which help understand the effect of the traditional process for phosphorus removal, and facilitate the development of coagulants and filter media of high effect.

\section{Experimental Material and Apparatus}

The influent water is from Zhuan River which is a surface water in Beijing. Figure 1 shows the schematic diagram of the experimental apparatus, which includes 3 mixing cups, 3 reacting cups, 1 inclined pipe, 2 filtration columns, 3 magnetic stirring bar apparatus, 3 mechanical stirrers, 1 raw water tank, 1 coagulant dissolving tank and 1 backwashing pump. In the mixing cup, the coagulant mixes with raw water. The coagulant reacts with raw water in the reacting cup. The water backwashing rate is $6 \mathrm{~L} / \mathrm{h}$. The time of mixing and coagulating is 15 min, the settling time is $20 \mathrm{~min}$ and the filtrating rate is $5 \mathrm{~m} / \mathrm{h}$.

\section{Phosphorus Removal Rate of PAC + AAL Process}

\subsection{The Effect of Phosphorus Removal}

The PAC and AAL were used together in water treatment process to remove phosphorus. The coagulant is poly aluminum chloride which is added at $40 \mathrm{mg} / \mathrm{L}$. The particulate diameter of activated aluminum oxide is $1.2 \mathrm{~mm}$, and it was washed in $5 \%$ sulfate solution before use. The backwashing rate is $5-12 \mathrm{~L} / \mathrm{m}^{2} \cdot \mathrm{s}$ and the cycle time is

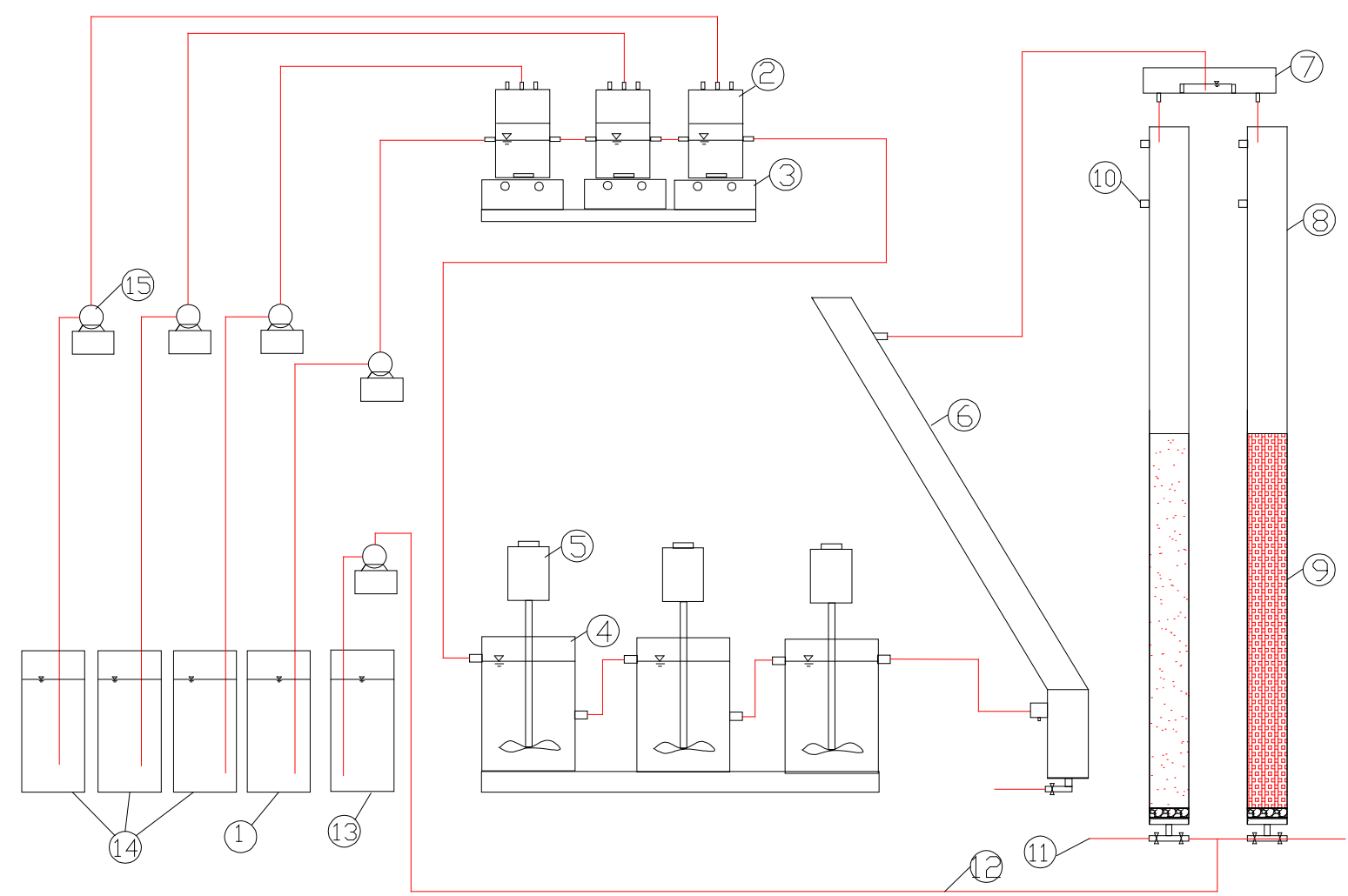

Figure 1. Sketch of the experimental device. Note: 1-raw water tank; 2-mixing cup; 3-magnetic stirring bar apparatus; 4-reacting cup; 5-stirring machine; 6-sedimentation tube; 7-distribution groove; 8-filtration column; 9-filter media; 10-overflow pipe; 11—effluent pipe; 12—backwash pipe; 13-backwash tank; 14—coagulation dissolving tank; 15-diaphragm pump. 
10 min. Activated aluminum oxide was recovered by aluminum sulfate solution. The effluent water quality was tested for total phosphorus after the running time of 1 hour, 2 hours, 4 hours, 8 hours, 16 hours and 24 hours, and the total phosphorus concentration was $99.57 \mu \mathrm{g} / \mathrm{L}$ as well. The experimental result was shown in Figure 2.

As shown in Figure 2, the removal rate of total phosphorus is $95 \%$ when the poly aluminum chloride was used with the filter media of activated aluminum oxide, and the filtration cycle is 8 hours. The average removal rate for total phosphorus ranged at $80 \%-95 \%$. It is known that the average removal rate for total phosphorus is in the range between $60 \%$ and $80 \%$ by poly aluminum chloride, and that of activated aluminum oxide is $70 \%$ $80 \%$, so technically the combined process should reach the average removal rate of $90 \%-95 \%$. Compared with the traditional process, the PAC + AAL process can depend on the adsorptive capacity of activated aluminum oxide to remove more phosphorus, especially the soluble phosphorus, which could be removed thoroughly in the coagulation stage by the adsorption of activated aluminum oxide.

In the process of filtration, the pollutants removal efficiency of adsorptive filter media by adsorption is greater than its physical interception capacity. Many researchers found there are many kinds of adsorptive filter media for removal of phosphorus. The basic mechanism of phosphorus removal by adsorptive filter media is adsorptive function, ion exchange and surface settlement, for the large specific surface area of the filter media.

One report [6] presented that the adsorptive capacity of a type of activated aluminum oxide for the soluble orthophosphate is $3950 \mu \mathrm{g} / \mathrm{L}$. A report concluded [7] that the adsorption isotherm is in line with the Langmuir model. The adsorptive theory of single molecular of Langmuir believes that any solid surface is not absolute smooth, and there is a great deal of embossing point on it. The atom and ion on the convex point have the unsaturated bonding force, which construct the adsorptive point that was referred to as surface adsorptive active core. When the phosphorus concentration of the raw water is great, the adsorptive point would be saturated rapidly, and then the removal rate of phosphorus would decline. As the phosphorus concentration is low, the most of surface active point reaches the saturation slowly, so the adsorptive amount would increase. While most active point has been saturated, the adsorptive capacity increases slowly with the increasing of phosphorus concentration. Once all of the active points have been saturated, the adsorptive capacity reach the largest capacity, so it would not increase with the increasing of phosphorus concentration.

Its adsorption function is one important reason for why the removal rate is large by activated aluminum oxide. Some research [8] indicated that the removal rate could reach over $80 \%$ for soluble phosphorus by activated aluminum oxide.

\subsection{Removal Efficiency for Various Size of Particulate Phosphorus}

The total phosphorus concentration of raw water is $77.86 \mu \mathrm{g} / \mathrm{L}$. The phosphorus of particulate size less than 0.1 $\mu \mathrm{m}$ is $6.97 \%$, the part that is at the range from 0.1 to $0.45 \mu \mathrm{m}$ is $12.20 \%$, the part between 0.45 and $1 \mu \mathrm{m}$ is $20.11 \%$, and the part larger than $1 \mu \mathrm{m}$ is $60.67 \%$. The dosage of poly aluminum chloride is $40 \mathrm{mg} / \mathrm{L}$, and the filtration rate is $5 \mathrm{~m} / \mathrm{h}$. The effluent water quality was tested after the running time of 1 hour, 2 hours, 4 hours and 12 hours, and the result was shown in Figure 3 and Figure 4.

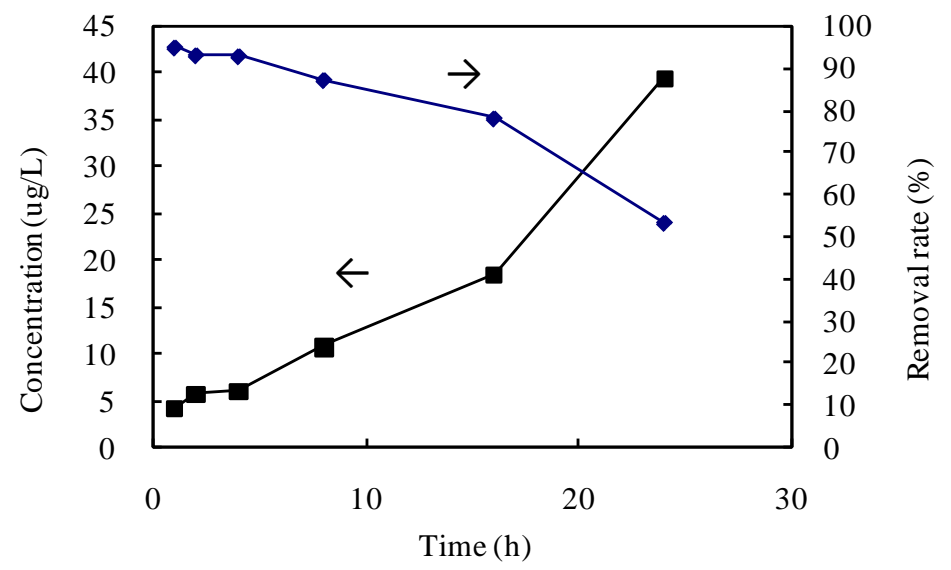

Figure 2. Effluent TP concentration and removal rate of PAC + AAL process. 


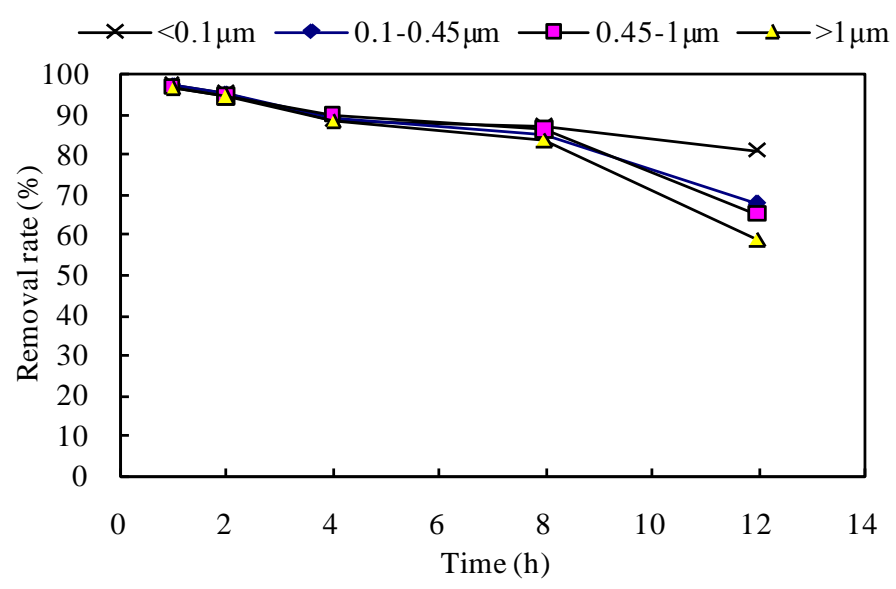

Figure 3. Removal rate of various size particulate phosphorus by PAC + AAL.

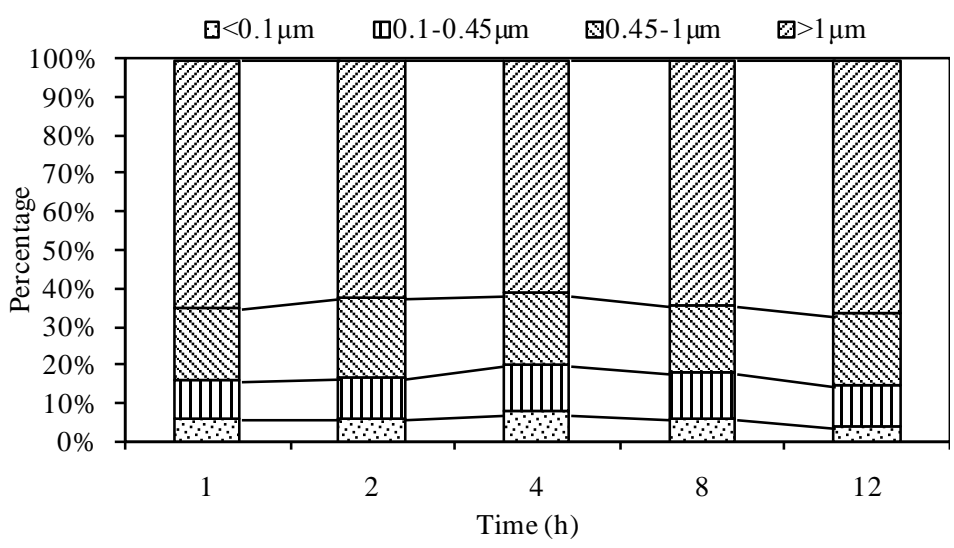

Figure 4. Effluent concentration proportion of different size particulate phosphorus.

Figure 3 sketches these relationships, for the combined process of poly aluminum chloride and activated aluminum oxide. As time went by, the effluent water particulate phosphorus concentration increase, and the removal rate drop. The speed of decreasing of soluble phosphorus is slow, but the particulate phosphorus decrease heavily. The phosphorus that size is larger than $1 \mu \mathrm{m}$ drop rapidly.

Figure 4 through column diagram provides the variety of proportion of every size of phosphorus. With the time going, the proportion of size larger than $1 \mu \mathrm{m}$ is increasing gradually. The phosphorus size is from $0.1 \mu \mathrm{m}$ to $1 \mu \mathrm{m}$ doesn't change. The part from $0.1 \mu \mathrm{m}$ to $0.45 \mu \mathrm{m}$ doesn't alter too. The part less than $0.1 \mu \mathrm{m}$ decrease gradually. Generally, the removal effect of particulate phosphorus that size is large is lower than that size is small. The most part of large size particulate phosphorus has been removed in coagulation process, and then the remnants were removed in filtration process. Therefore, the large size particulate phosphorus was affected by the saturated grade of filter media.

\section{Phosphorus Removal Experiment of PFS + AAL Process}

\subsection{Phosphorus Removal Efficiency}

The $\mathrm{pH}$ value of the raw water is 8.21 , at the same time the temperature was tested at $21^{\circ} \mathrm{C}$, and the total phosphorus concentration is $99.57 \mu \mathrm{g} / \mathrm{L}$. The PFS was added in the process with the dosage at $40 \mathrm{mg} / \mathrm{L}$. The AAL was used in the filtration column. The filtration rate was set at $5 \mathrm{~m} / \mathrm{h}$, and then the effluent water was tested for total phosphorus after the apparatus running for 1 hour, 2 hours, 4 hours, 8 hours, 16 hours and 24 hours. The result was shown in Figure 5. 
The trend of the removal rate is illustrated in Figure 5. The removal rate for phosphorus by process of poly ferric sulfate combined with activated aluminum oxide is in the range of $80 \%-97 \%$ within 16 hours. From above mentioned, the removal rate of phosphorus by poly ferric sulfate is from $70 \%$ to $85 \%$, and that by activated aluminum oxide is from $70 \%$ to $80 \%$, so that by the combined process should range at $93 \%-97 \%$. The filtration period of time is 8 hours, and the effluent water total phosphorus start to surpass the $10 \mu \mathrm{g} / \mathrm{L}$ after 8 hours. Researches have illustrated that the best $\mathrm{pH}$ value is 6 by activated aluminum oxide for phosphorus [9], and the removal efficiency for soluble phosphorus is better.

Report [10] has conducted that the proportion of every size of phosphorus varies little in this river, and the poly ferric sulfate could remove total phosphorus at the rate of $80 \%$, the reactive soluble phosphorus of $100 \%$ as well.

\subsection{The Removal Efficiency of Various Size of Particulate Phosphorus}

The raw water was tested for total phosphorus at $86.52 \mu \mathrm{g} / \mathrm{L}$. The phosphorus particulate size less than $0.1 \mu \mathrm{m}$ is $9.03 \%$, that of $0.1-0.45 \mu \mathrm{m}$ is $9.27 \%$, that at $0.45-1 \mu \mathrm{m}$ is $19.91 \%$, and that greater than $1 \mu \mathrm{m}$ is $61.79 \%$. The graphical representation of this result is shown in Figure 6 and Figure 7.

As can be seen from the Figure 7, the proportion of every size of particulate phosphorus does change little. It illustrated that removal rate of every size of particulate phosphorus are identical, and the change of removal rate of every size is basically the same. Although the function of activated aluminum oxide begin to fade, yet the

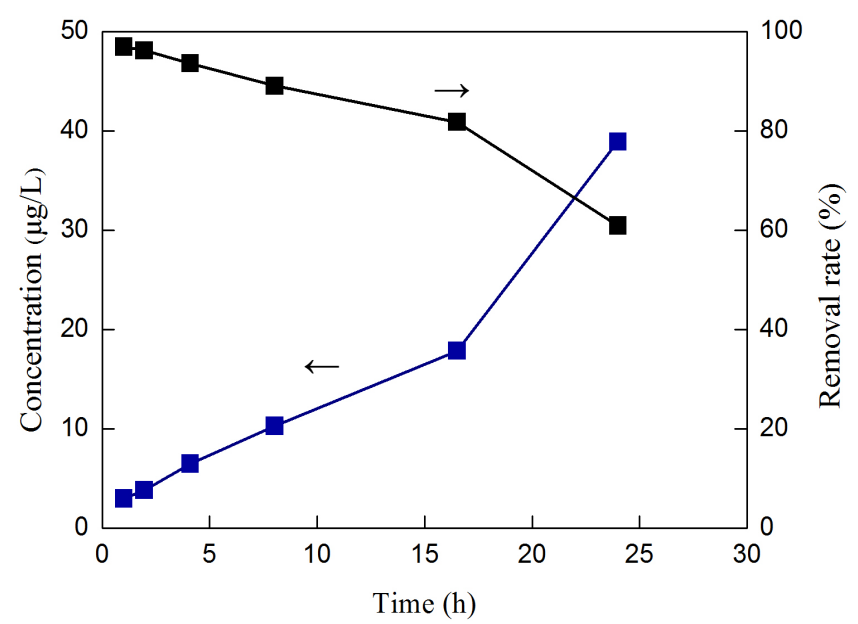

Figure 5. Effluent TP concentration and removal rate of PFS + AAL process.

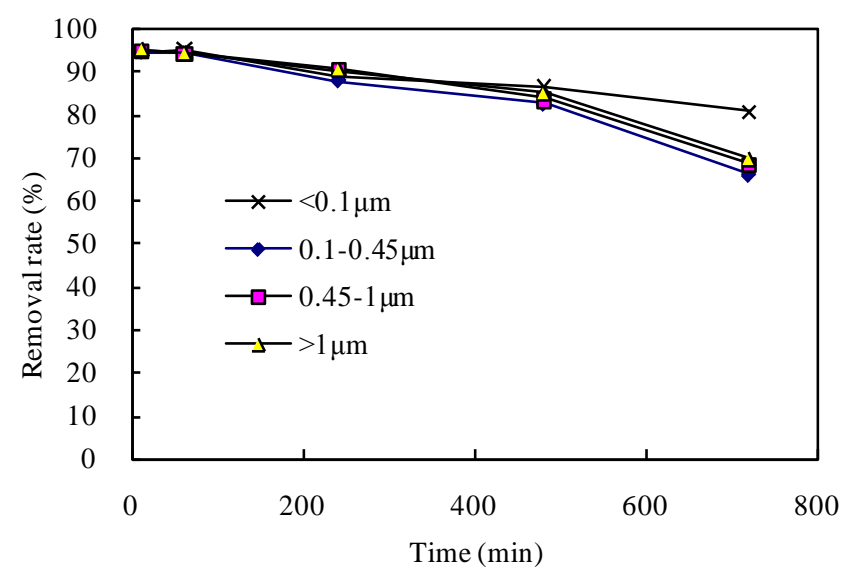

Figure 6. Removal rate of various size particulate phosphorus of PFS + AAL. 
removal rate of every size of particulate decline at the same time. Because the soluble phosphorus only take the $20 \%$ of total phosphorus, but the particulate phosphorus removed took $80 \%$. After the coagulating, the soluble phosphorus reduced to less, so the activated aluminum can't execute the advantage of adsorption. On the one hand, the activated aluminum executes physical capture ability to intercept the particulate phosphorus. On the other hand, the activated aluminum oxide executes the adsorptive capacity to remove soluble phosphorus. Therefore, all kinds of phosphorus were removed by this two functions. Although it reaches the end of the life of filter media, yet the activated aluminum oxide does not reach the saturated status, maybe it only meet the end of the physical interception.

\subsection{Water Quality Index}

The effluent of process of PFS + AAL was tested, which use the PFS as the coagulant, and operate for 7 hours. The index tested includes $\mathrm{COD}_{\mathrm{Mn}}$, color and turbidity. The result was shown in Table 1.

As a result, all of the indexes meet the requirement of standards for drinking water quality (GB5749-2006).

\section{Comparison of Processes}

As shown in Figure 8 and Table 2, the total phosphorus in effluent water of two processes are both in the range from 3 to $10 \mu \mathrm{g} / \mathrm{L}$, and the total phosphorus removal rate can reach up to $97 \%$ for PFS + AAL as well as $95 \%$ for PAC + AAL. If the $10 \mu \mathrm{g} / \mathrm{L}$ is the standard of biological stability, the effluent can reach the biological stability. Because the aluminum has harm to the central nervous system and organs of creature, furthermore, people have recognized the potential harm of aluminum salt, so the aluminum has been prohibited gradually. So the process of PFS + AAL would be the best one to be used in water plant for phosphorus removal.

\section{Conclusion}

In conclusion, both the PAC + AAL and PFS + AAL could remove the phosphorus to the level below $10 \mu \mathrm{g} / \mathrm{L}$

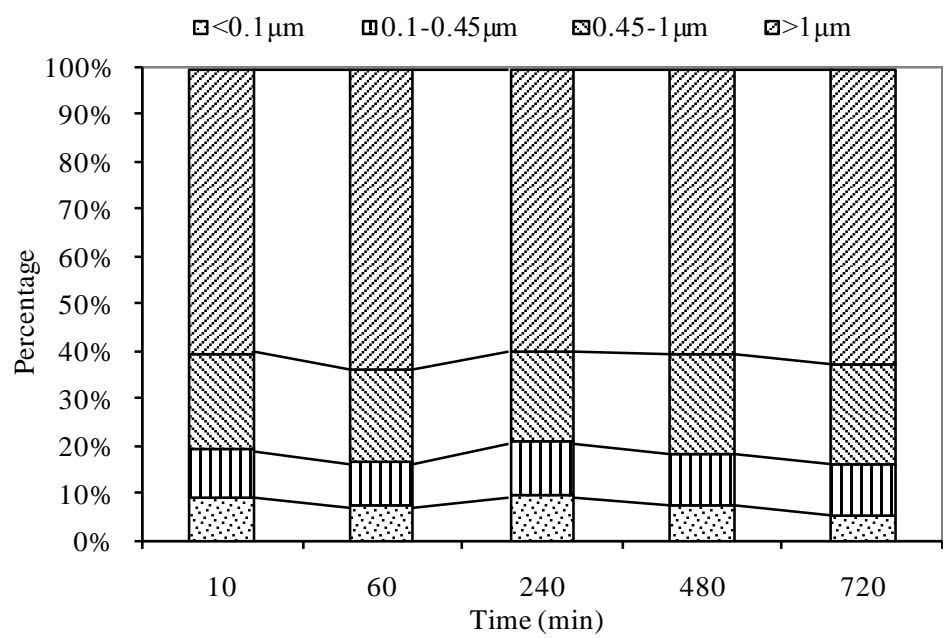

Figure 7. Effluent concentration proportion of different size particulate phosphours.

Table 1. Effluent quality of PFS + AAL.

\begin{tabular}{cccccc}
\hline & $\begin{array}{c}\text { Total phosphorus } \\
(\mu \mathrm{g} / \mathrm{L})\end{array}$ & $\mathrm{pH}$ & $\begin{array}{c}\text { Color } \\
(\text { degree })\end{array}$ & $\begin{array}{c}\text { Turbidity } \\
(\mathrm{NTU})\end{array}$ & $\begin{array}{c}\text { CODMn } \\
(\mathrm{mg} / \mathrm{L})\end{array}$ \\
\hline Raw water & 58.34 & 8.06 & 1.33 & 5.91 & 4.73 \\
Coagulation and sedimentation & 11.72 & 7.55 & 0.18 & 2.7 & 2.55 \\
After filtration & 3.05 & 7.98 & 0.06 & 0.74 & 1.36 \\
Removal rate (\%) & 94.8 & - & 95.5 & 73.8 & 71.2 \\
Drinking water quality (GB5749-2006) & - & $6.5-8.5$ & 15 & 1 & 3
\end{tabular}




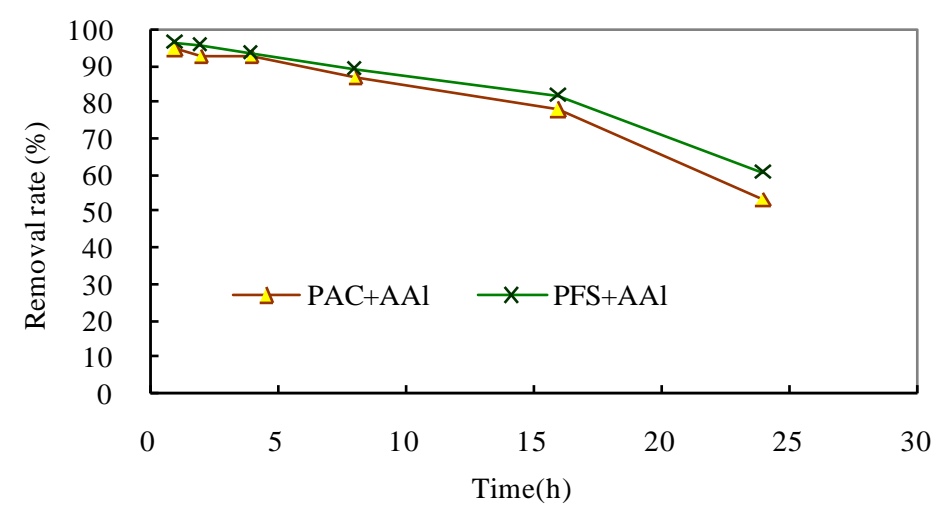

Figure 8. Comparison of TP removal rate of two processes.

Table 2. Phosphorus removal efficiency comparison of two processes.

\begin{tabular}{ccccccc}
\hline $\begin{array}{c}\text { Treatment } \\
\text { process }\end{array}$ & $\begin{array}{c}\text { Dosage added } \\
(\mathrm{mg} / \mathrm{L})\end{array}$ & $\begin{array}{c}\text { Filtration cycle } \\
(\mathrm{h})\end{array}$ & $\begin{array}{c}\text { Influent TP } \\
(\mu \mathrm{g} / \mathrm{L})\end{array}$ & $\begin{array}{c}\text { Effluent TP } \\
(\mu \mathrm{g} / \mathrm{L})\end{array}$ & $\begin{array}{c}\text { Average TP } \\
(\mu \mathrm{g} / \mathrm{L})\end{array}$ & $\begin{array}{c}\text { TP removal rate } \\
(\%)\end{array}$ \\
\hline PAC + AAL & 40 & 8 & 99.6 & $3-10$ & 5.4 & $90-95$ \\
PFS + AAL & 40 & 8 & 99.6 & $3-10$ & 4.6 & $93-97$ \\
\hline
\end{tabular}

which is the standard of biological stability. On one hand, the coagulation and sedimentation execute the function to remove the phosphorus. On the other hand, the filter media which has high capacity of adsorption was used in filtration process. So the adsorptive filter media is helpful to enhance the removal of phosphorus in the water plant, and the PFS + AAL would be the best process to be used in water plant for phosphorus removal.

\section{Acknowledgements}

This work was financed by Key Science and Technology Financing Projects of Ministry of Education (211002), General Program of Science and Technology Development Project of Beijing Municipal Education Commission (KM201110016009) and Major Science and Technology Program for Water Pollution Control and Treatment (2010ZX07320-002).

\section{References}

[1] Miettinen, I.T., Vartiainen, T. and Martikainen, P.J. (1997) Phosphorus and Bacterial Growth in Drinking Water. Applied and Environmental Microbiology, 63, 3242-3245.

[2] Xin, Y., Zhang, Z. and Wang, Z. (2003) Phosphorus as a Limiting Nutrient in Drinking Water Biological Treatment. Environmental Science, 24, 57-62.

[3] Sang, J., Yu, G., Zhang, X. and Wang, Z. (2003) Relation between Phosphorus and Bacterial Regrowth in Drinking Water. Environmental Science, 24, 81-84.

[4] Sang, J., Zhang, X., Zhou, H. and Wang, Z. (2003) Study on Total Phosphorus as Controlling Parameter of Drinking Water Biological Stability. Advances in Water Science, 14, 720-724.

[5] Sathasivan, A., Ohgaki, S., Yamamoto, K. and Kamiko, N. (1997) Role of Inorganic Phosphorus in Controlling Regrowth in Water Distribution System. Water Science and Technology, 35, 37-44. http://dx.doi.org/10.1016/S0273-1223(97)00149-2

[6] Feng, Q. (2007) Study on Advanced Treatment Technique of Phosphorus Removal in Drinking Water. Thesis, Beijing University of Technology, Beijing.

[7] Wang, J., Zhang, Y., Feng, C., Wang, H. and Wang, L. (2010) Adsorption Capacity Comparison among Three Filter Media for Phosphorus. 2010 4th International Conference on Bioinformatics and Biomedical Engineering, Chengdu, 18-20 June 2010, 1-4. http://dx.doi.org/10.1109/icbbe.2010.5516223

[8] Wang, J., Wu, J., Long, Y. and Li, G. (2007) Comparison on Phosphorus and Turbidity Removal by Activated Aluminum and Other Filter Materials. Chinese Journal of Environmental Engineering, 1, 18-21. 
[9] Wang, J., Feng, C., Yang, Y., Long, Y. and Li, G. (2008) Experiment on Phosphorus Removal by Activated Alumina. Journal of Beijing University of Technology, 34, 621-625.

[10] Wang, J., Long, Y., Che, W., Li, G. and Yang, Y. (2008) Existing Forms of Phosphorus in Rivers and Removal Efficiency by Coagulation. Water Resources Protection, 24, 87-90. 